\title{
The Role of School Quality Assurance in Improving Curriculum Implementation in Secondary Schools in Tanzania
}

\author{
Leonard T. Burra* Ibrahim M. Fanuel \\ Agency for the Development of Educational Management (ADEM), P.O. Box 1234, Mwanza-Tanzania
}

\begin{abstract}
The purpose of the study was to assess the role of school quality assurance in improving curriculum implementation in secondary schools in Tanzania. Specifically, the study intended to determine strategies used by SQAs to enhance secondary school curriculum implementation and examined the usefulness of school quality assurance reports in improving secondary school curriculum implementation. The study employed a crosssectional descriptive design to collect data from 166 respondents using interview guides, questionnaires and documentary review. The study reveals that: SQAs insisted on the use of academic documents as well as conducting internal school quality assurance as the strategies to improve curriculum implementation and the SQA report gives an overall picture of the position of the school in the aspects of curriculum implementation. It was concluded that SQAs play a great role in ensuring proper implementation of the curriculum in schools, however, SQA alone could not be an adequate factor for improving curriculum implementation.
\end{abstract}

Keywords: school quality assurance, curriculum implementation

DOI: $10.7176 / \mathrm{JEP} / 12-2-10$

Publication date: January $31^{\text {st }} 2021$

\section{Introduction}

Curriculum implementation is the core function of every training institution. It is a well-organized course of study necessary to achieve the desired performance. A curriculum is a programme of goals in which certain skills, knowledge and attitudes are imparted to learners so as to accomplish a certain level of training. In Tanzania, the standard indicators for the successfulness of curriculum goals are respectable performance in assessment both formative and summative. At secondary school level, both ordinary and advanced levels, assessment of the attainment of the curriculum goals are assessed by the National Examination Council of Tanzania (NECTA) through Certificate of Secondary Education Examinations (CSEE) and Advanced Certificate of Secondary Education Examinations (ACSEE).

There had been a prolonged public outcry on the unpromising examination performance in Tanzania as reflected in CSEE and ACSEE performance. The poor performance is also recognized by the Education and Training Policy (ETP) of 2014. It stipulates that secondary examination performance has been dramatically dropping with a sharp slope from $90 \%$ in 2007 to $43 \%$ in 2012 (URT, 2014). For instance, Table 1 presents the trend of the percentage of students who scored divisions IV and 0 judged to be poor performance in CSEE from 2014 to 2018.

Table 1: Percentage of students scored Division IV and 0
\begin{tabular}{|l|c|c|c|}
\hline YEAR & Division IV & FAILED & TOTAL \\
\hline 2014 & 39 & 30.2 & 69.2 \\
\hline 2015 & 42.6 & 32 & 74.6 \\
\hline 2016 & 42.8 & 29.7 & 72.5 \\
\hline 2017 & 47.4 & 22.4 & 69.8 \\
\hline 2018 & 47.5 & 20.7 & 68.2 \\
\hline
\end{tabular}

Source: (BEST, 2019)

In Tanzania, there are several entities responsible for ensuring that the secondary school curriculum is properly implemented in order to achieve better performance. School Quality Assurance (SQA) unit formerly School Inspectorate, is one of those entities established to ensure compliance to policies, laws, regulations and other standard-setting instruments in the delivery of basic education at all levels. The SQA is an internal and external process of promoting, supporting, and imparting agreed quality standards for all aspects of school life to ensure that acceptable standards are attained and that there is continuous improvement through rigorous monitoring, evaluation, taking action, and reporting on quality standards (URT, 2017).

When schools are effectively monitored by SQAs, the quality of education is likely to be achieved as students and teachers are actively involved in the teaching and learning process. Ochuba (2008) cited by Onugu (2009) states that school inspectorate currently termed as SQA is a key component of overseeing, managing, monitoring and controlling education system and curriculum implementation. On the other hand, URT (2006) argues that school inspection is a fundamental practice of making checks and balances in the delivery of education through closer monitoring as well as acting as the feed-back mechanism. 

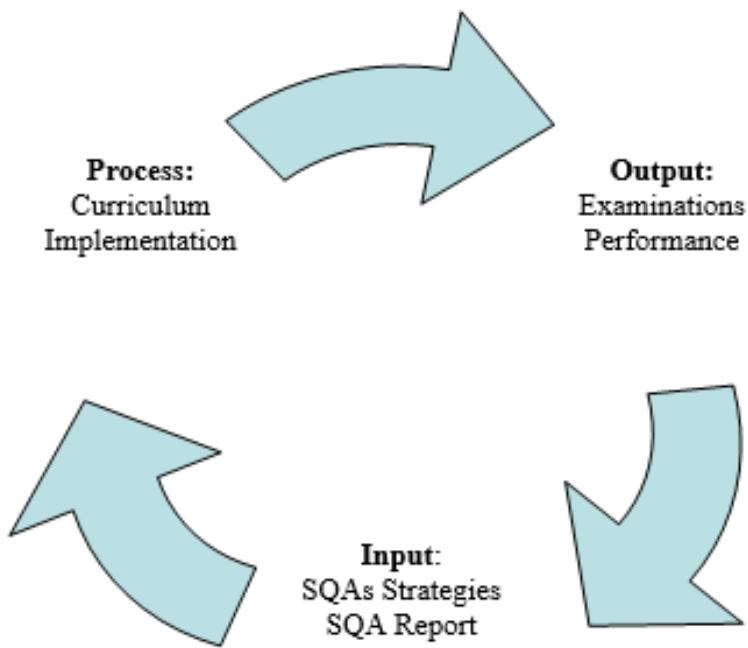

\section{Input: \\ SQAs Strategies \\ SQA Report}

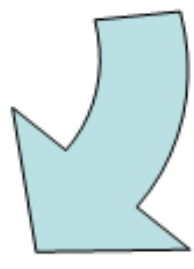

Figure 1:Conceptual Framework

However, some challenges hinder effective School Quality Assurance. These challenges are based on professionalism, attitudes, commitment, feedback, and follow-up. Such challenges need to be constantly identified and addressed so that they do not disrupt the positive yields of the school quality assurance process (Wanzare, 2002). This study bridges the gap resulted from persistent claims of secondary schools' products that do not meet stakeholders' expectations. Therefore, the study assessed the role played by SQAs in improving secondary school curriculum implementation. Explicitly, the study determined strategies used by SQAs to enhance secondary school curriculum implementation and examined the usefulness of school quality assurance reports in improving secondary school curriculum implementation.

\section{Methods and materials}

The study employed descriptive design to collect data from 166 respondents from selected secondary schools in Manyara Region of North-Western School Quality Assurance Zone-Tanzania. Purposive sampling technique was used to select District Education Officers (DEOs), and Heads of Schools (HoS) while random sampling was used to select Zonal School Quality Assurers (ZSQAs), subject teachers, School Governing Boards Members (SGBMs) and students.

Several appropriate methods of data collection were used to gather information related to the study. Interview guides were used to collect data from DEOs, HoS, ZSQAs and SGBMs while questionnaires were used to collect data from subject teachers and students. Data collected through questionnaires and interview guides were cleaned, organized, and processed through Excel. The descriptive analysis was done to generate frequency distribution tables, charts and texts, whereas the qualitative information was subjected to paraphrasing the contents into meaningful quotes and themes.

\section{Results and discussions}

The presentation of the key findings of the study was based on the specific objectives of the study which were to: determine strategies used by SQAs to enhance secondary school curriculum implementation and examined the usefulness of school quality assurance reports in improving secondary school curriculum implementation.

\subsection{Strategies used by SQAs to improve curriculum implementation}

This objective intended to determine different strategies employed by SQAs to ensure proper implementation of the secondary school curriculum. To respond to this objective, the following questions were used as a guide:

What areas do SQAs emphasize during a school visit?

What kind of assistance do SQAs provide to teachers?

\subsubsection{Areas SQAs emphasize during a school visit}

The findings from the study reveal that SQAs often emphasize the proper use of academic documents that guide teachers during the teaching and learning process. Table 2 shows the summary of interview responses from HoS about the areas of curriculum implementation emphasized by SQAs. 
Table 2: SQAs Emphasis areas $\mathrm{N}=13$

Areas of Curriculum Implementation

Preparations, use, and adherence to academic documents

Use of proper teaching methods, techniques, and strategies

Availability, use, and coverage of proper syllabus

Use of remedial teaching for slow learners and for schools

with scarcity of teachers

Use of proper books with Education Materials Approval Committee (EMAC)

\begin{tabular}{cc} 
& $\mathrm{N}=13$ \\
\hline Respondents & Percentage $(\%)$ \\
11 & 84.62 \\
6 & 46.15 \\
3 & 23.08 \\
3 & 23.08 \\
2 & 15.38
\end{tabular}

The findings presented in Table 2 reveal that SQA's more emphasis is on preparations, use, and adherence to academic documents $(84.62 \%)$ while paying less attention to the use of proper books with the Education Materials Approval Committee (EMAC) $(15.38 \%)$.

However, effective curriculum implementation is the combination of proper use and coverage of syllabus; effective utilization of learning times; proper use of methods and techniques of teaching and learning; proper record keeping of students' progress; and proper use of teaching and learning materials (URT, 2006). Paying attention to certain aspects while ignoring other aspects will likely threaten effective implementation of the curriculum.

\subsubsection{Aspects of assistance provided to teachers by SQAs}

On the other hand, teachers respond to questionnaires on aspects in which they are assisted by SQAs to improve curriculum implementation.

Table 3: Aspects of assistance provided to teachers

\begin{tabular}{lc} 
Table 3: Aspects of assistance provided to teachers & $\mathrm{N}=43$ \\
\hline Aspects of assistance & Percentage \\
\hline Preparation of lesson plans & 79.07 \\
Teaching techniques, strategies and methods & 65.12 \\
Filling subject logbooks & 60.47 \\
Preparation of Schemes of works & 60.47 \\
Preparation of Lessons Notes & 46.51 \\
Use of teaching materials & 27.91 \\
Time management & 25.58 \\
Student evaluation & 18.60 \\
\hline
\end{tabular}

The findings in Table 3 concur with the findings in Table 2 as teachers working documents were highly given priority by SQAs during their visit. Teachers were mostly assisted in the preparation of lessons plan (79.07\%); teaching techniques, strategies and methods (65.12\%); filling subject logbooks $(60.47 \%)$ and preparation of schemes of works $(60.47 \%)$. However, less attention was paid to student evaluation $(18.60 \%)$. From the findings, documents connected to students are somehow ignored by SQAs $(18.60 \%)$ which poses a question to whether SQAs executes their roles of ensuring curriculum implementation in secondary schools.

It is of paramount importance that, students' evaluation to be given high consideration by SQAs because curriculum implementation is incomplete if the aspects of students' evaluation are ignored. URT (2006) and Harris (1963) stipulate that SQAs should ensure that students' work is thoroughly marked, corrected, and recorded to determine whether students are growing in the directions accepted by society, curriculum planners, parents, or by teachers. Moreover, Bediako (2019) argues that students are a critical element in curriculum implementation while teachers are the arbiters of the classroom practice. Students hold the key to what is implemented from the curriculum. They influence teachers in their selection of learning experiences, hence the need to consider the diverse characteristics of learners in curriculum implementation.

\subsection{The usefulness of SQAs reports}

Further, the study examined the usefulness of SQAs report in improving curriculum implementation. Through questionnaires, teachers provided the usefulness of SQAs report as presented in Table 4

Table 4: Usefulness of SQAs report

\begin{tabular}{lc}
\hline Responses & Percentage \\
\hline It is a tool used in monitoring and evaluation of a school & 45 \\
Provides the category of a school & 40 \\
Shows areas of weaknesses and strengths & 32 \\
It motivates teaching staffs and management & 31 \\
Teachers and management become aware of areas to improve & 21 \\
It mirrors the school towards community & 16 \\
\hline
\end{tabular}

Table 4 reveals that SQA report is useful as it is a tool used in the monitoring and evaluation of a school $(45 \%)$. However, the report seems not to be useful in showing the position or relationship between the school and 
community $(16 \%)$. This can be attributed to the fact that in Tanzania SQAs report lacks parents' views about the school (URT, 2006). Furthermore, one DEO during an interview said:

Parents and School Governing Board who are important stakeholders in curriculum implementation are not given the SQAs reports. They get indirect information about school inspection from meetings by government officials.

The findings are in line with Al Karam, Al Marri, and Al Muhairi (2009) and Macnab (2001) who assert that the SQAs reports show how schools and students are performing, inform parents about the quality of schools, inform teachers about the effectiveness, enlighten the head of school how well their schools are performing and tell the education authorities and the governing bodies about the overall quality of schools.

\section{Conclusions}

Improved curriculum implementation is a very crucial factor in attaining proper education. In this study, the findings reveal that SQA's put much emphasis on teachers working documents as the strategies to supervise curriculum implementation and produce a report which is used as a tool for school monitoring and evaluation. However, it had been discovered that SQAs alone could not be an adequate factor for improving curriculum implementation in secondary schools. Factors such as availability of teaching and learning resources, enough teachers, libraries, laboratories, good command of the language of instruction and proper time management in conjunction with SQA supervision could lead to the realization of an improved curriculum. For curriculum implementation to be improved there is a need for collective efforts from various stakeholders such as communities, teachers, students, parents, representatives of educational organizations, government, and local education authorities.

\section{REFERENCES}

Al Karam, A. et.al. (2009). The role of international assessments and school inspections in the reform of education in Dubai. Dubai: KHDA.

Bediako, S. (2019). Models and concepts of curriculum implementation, some definitions and influence of implementation. Unpublished Manuscript, University of Cape Coast.

Cohen, L. et.al. (2000). Research methods in education, London: Routledge Falmer.

Macnab, D. (2001). Curriculum development and HM inspection of schools: A scottish case study. Oxford Review of Education. 27(1), 85-101. London: Taylor \& Francis, Ltd.

United Republic of Tanzania. (2018). Education Sector Development Plan. Dar es Salaam. Ministry of Education, Science and Technology.

United Republic of Tanzania. (2004). Education Sector Development Programme (ESDP): Secondary Education Development plan (SEDP) 2004 - 2009. Dar es Salaam: Ministry of Education and Culture.

Jamhuri ya Muungano wa Tanzania. (2006). Kiongozi cha mkaguzi wa shule.Dar es Salaam: Wizara ya Elimu na Mafunzo ya Ufundi.

United Republic of Tanzania. (2019). Basic education statistics. Dar es Salaam: Ministry of Education and Vocational Training.

United Republic of Tanzania. (2017). School Quality Assurance Handbook. Ministry of Education, Science and Technology. 